\title{
Numerical Simulation of the Shear Behaviour of Cement Grout
}

\author{
Jianhang Chen $\mathbb{D}$, ${ }^{1,2}$ Fan Zhang $\mathbb{D}^{1},{ }^{1}$ Hongbao Zhao $\mathbb{D},{ }^{1}$ and Junwen Zhang $\mathbb{D}^{1}$ \\ ${ }^{1}$ School of Energy and Mining Engineering, China University of Mining and Technology (Beijing), Beijing 100083, China \\ ${ }^{2}$ International Joint Research Laboratory of Henan Province for Underground Space Development and Disaster Prevention, \\ Henan Polytechnic University, Jiaozuo 454003, China
}

Correspondence should be addressed to Junwen Zhang; zhangjunwen1977@163.com

Received 7 April 2021; Accepted 15 June 2021; Published 23 June 2021

Academic Editor: Shengwen Tang

Copyright ( 2021 Jianhang Chen et al. This is an open access article distributed under the Creative Commons Attribution License, which permits unrestricted use, distribution, and reproduction in any medium, provided the original work is properly cited.

\begin{abstract}
Cement grout is widely used in civil engineering and mining engineering. The shear behaviour of the cement grout plays an important role in determining the stability of the systems. To better understand the shear behaviour of the cement grout, numerical direct shear tests were conducted. Cylindrical cement grout samples with two different strengths were created and simulated. The numerical results were compared and validated with experimental results. It was found that, in the direct shear process, although the applied normal stress was constant, the normal stress on the contacted shear failure plane was variable. Before the shear strength point, the normal stress increased slightly. Then, it decreased gradually. Moreover, there was a nonuniform distribution of the normal stress on the contacted shear failure plane. This nonuniform distribution was more apparent when the shear displacement reached the shear strength point. Additionally, there was a shear stress distribution on the contacted shear failure plane. However, at the beginning of the direct shear test, the relative difference of the shear stresses was quite small. In this stage, the shear stress distribution can be assumed uniform on the contacted shear failure plane. However, once the shear displacement increased to around the shear strength point, the relative difference of the shear stresses was obvious. In this stage, there was an apparent nonuniform shear stress distribution on the contacted shear failure plane.
\end{abstract}

\section{Introduction}

Cement is grey fine powder that is widely used in civil engineering and mining engineering $[1,2]$. In civil engineering, as an important ingredient, cement is always mixed with water, sand, and rocks to form concrete, which is the commonly used construction or building material $[3,4]$. In mining engineering, cement is usually mixed with water to form the cement grout, which is then poured into drilled boreholes to bond the reinforcing tendon, such as rock bolts and cable bolts, with the surrounding rock masses [5]. Moreover, the cement can be used as the grouting material to be poured into rock mass to improve its mechanical behaviour.

The mechanical properties of the cement grout have a significant effect in deciding the performance of the rock reinforcement systems [6]. Consequently, a vast of research has been conducted to study the mechanical behaviour of cement grout [7]. Those studies can be basically divided into studying the axial behaviour of the cement grout and shear behaviour of the cement grout.

To study the axial behaviour of the cement grout, researchers mainly used the Uniaxial Compressive Strength (UCS) tests. Feldman and Beaudoin [8] indicated that the strength and Young's modulus of the Portland cement grout were largely influenced by the porosity. Domone and Thurairatnam [9] found that with the water/cement $(w / c)$ ratio decreasing, the strength of the cement grout increased. Hyett et al. [10] evaluated the influence of curing time on the grout strength and found that the grout UCS increased nonlinearly with the hydration time ranging from 1 to 7 days. Boumiz et al. [11] adopted the ultrasonic and calorimetric methods on cement grout. They found that the larger the hydration degree, the higher the Young's modulus of the cement grout. Li et al. [12] studied the influence of nanoparticles on the performance of cement grout. They proved that adding nanoparticles was beneficial for improving the grout strength. Mirza et al. [13] revealed that the grout 
strength increased within the curing period, independent of the cement type.

The above research played an important role in revealing the mechanical performance of cement grout. However, experimental tests proved that in the fully grouted rock reinforcing system, failure of the system usually occurred at the bolt/grout interface [14]. This was caused by the low shear strength of the interface [15]. The shear behaviour of the cement grout has a significant role in determining the shear strength of the bolt/grout interface [16]. Therefore, a better understanding of the shear behaviour of the cement grout was beneficial for preventing the failure of the bolt/ grout interface.

To study the shear behaviour of cement grout, researchers commonly used triaxial tests and direct shear tests. For triaxial tests, Hyett et al. [17] studied the performance of Portland cement grout with the confining pressure ranging from $5 \mathrm{MPa}$ to $15 \mathrm{MPa}$. The results showed that the larger the confining pressure, the higher the strength of the cement grout. Moreover, the cohesion and the internal friction angle were successfully acquired. Simms and Grabinsky [18] performed triaxial tests on cement material under the confined condition. The results showed that in the shearing process, the cementitious material had an apparent tendency to dilate. Sakai et al. [19] studied the performance of the cement paste under the triaxial condition. The results proved that increasing the confining pressure changed the sample failure mode. Specifically, when the confining pressure was $30 \mathrm{MPa}$, an oblique shear failure plane occurred in the sample. However, once the confining pressure was much larger, a horizontal failure plane occurred in the sample. Aziz et al. [20] conducted triaxial tests on two types of cement grout and used Mohr-Coulomb (MC) model to fit the shear strength envelope. A vast of triaxial tests were conducted by Chen and $\mathrm{Xu}$ [21] to study the performance of the cement grout under the high confining pressure condition. It was found that with the confining pressure increasing, the performance of the cement grout changed from brittle to ductile. Moreover, this phenomenon was valid independent of the $w / c$ ratio. Those triaxial testing research improved the understanding of the shear behaviour of cement grout. However, in triaxial tests, the shear failure plane occurred dependent on the properties of the grout and the loading status [22]. This was not a true reflection of the shear failure of the bolt/grout interface in the rock reinforcing system, in which the shear failure plane was a predefined plane $[23,24]$.

Therefore, the direct shear test was a better approach to study the shear behaviour of the cement grout for the rock reinforcement scenario. The direct shear test is a traditional method to evaluate the shear strength of a material. Normally, a shear box is prepared. Then, the tested sample is cut to the desired geometry with the required dimension. After that, the sample was set in the shear box and installed in the apparatus. Operators can apply normal stress on the sample and then apply shear velocity along the shear direction. This test is continued until the shear strength was obtained. In this way, the shear strength of the material can be acquired. Moosavi and Bawden [25] designed a shear box to conduct direct shear tests on Portland cement grout. The results showed that the direct shear test was likely to provide a smaller shear strength of the cement grout when compared with triaxial tests. Lu and Wang [26] performed direct shear tests on cementitious samples with two different $w / c$ ratios: 0.3 and 0.4 . They found that when the $w / c$ ratio was 0.3 , the shear strength of the cement-based sample increased apparently with normal stress. However, when the $w / c$ ratio was 0.4 , the shear strength of the cement-based sample did not increase much with the normal stress. Assaad et al. [27] proposed using the direct shear test to study the yield stress of cement material. The results revealed that the material shear strength was largely dependent on the normal stress, following the MC rule. Chen et al. [28] compared the shear performance of a Portland cement grout under the constant normal load and constant normal stiffness condition. It was found that the boundary condition might influence the performance of the cement grout. Li et al. [29] adopted the direct shear tests to investigate the influence of particle size on the shear strength of cement grout. They found that by adding superfine cement, the early-age shear strength parameters of the cement grout can be largely enhanced.

Those research provided new insights and knowledge in revealing the shear performance of cement grout. However, most research was conducted with experimental tests. Compared with that, much less work has been performed via numerical simulation. Therefore, this study aims at studying the shear behaviour of the cement grout with numerical simulation.

First, a numerical calculating program was selected to conduct this research. After that, numerical direct shear tests were performed to evaluate the shear behaviour of the cement grout. Then, the numerical calculating results were validated with experimental results. Last, the shear stress distribution on the shear failure plane was investigated.

\section{Selection of the Software}

In this study, the three-dimensional software FLAC3D (Fast Lagrangian Analysis of Continua in 3 Dimensions) was used. This program was developed by the Itasca Consulting Group.

The reason to use this program is that the Itasca Company developed the interface element in it. This interface element is composed of triangular elements and corresponding nodes. Moreover, the interface element is defined with the shear coupling constitutive law. In this case, once shear displacement occurs in the interface element, shear stress at the interface accumulates and can be calculated. Relying on this function, the shear behaviour of a material can be studied.

The authors of this study previously used the two-dimensional software FLAC to simulate the shear failure process of the bolt/grout interface [30]. However, the drawback was that the problem was simplified to be twodimensional. Compared with FLAC, the advantage of FLAC3D was that it could simulate objects in three dimensions. Therefore, it can better reflect the mechanical behaviour of objects. Then, in this study, the FLAC3D was used to simulate the shearing process of the cement grout. 


\section{Numerical Simulation Process}

A vast of direct shear tests were performed by Moosavi and Bawden [25]. Those tests were used in this study and simulated with FLAC3D. In their study, two different $w / c$ ratios were used, namely, 0.4 and 0.5 . Then, in the following section, numerical tests on those two cement grouts were performed.

\subsection{Simulation of the Cement Grout with a Higher Strength}

3.1.1. Numerical UCS Test and Validation. Before the direct shear test was conducted, UCS tests were performed to acquire the basic mechanical properties of the grout, including the UCS, Young's modulus, and Poisson's ratio. Detailed information about the UCS test process and results were reported by Moosavi [23]. Experimental results showed that for the cement grout with a $w / c$ ratio of 0.4 , the UCS, Young's modulus, and Poisson's ratio were $50.6 \mathrm{MPa}$, $12.66 \mathrm{GPa}$, and 0.25 . More specifically, in the UCS test, the cement grout was filled in PVC tubes with a diameter of $50 \mathrm{~mm}$ and a length of $150 \mathrm{~mm}$.

In the numerical simulation in FLAC3D, the $w / c$ ratio cannot be directly simulated. As a compromise, the UCS of the numerical mesh was selected as the index to compare with the experimental result. In FLAC3D, a numerical UCS test was created as shown in Figure 1.

In the numerical UCS test, a cylindrical mesh was established. At the top and bottom of the cylinder, two square steel plates were established to simulate the loading plates. The whole mesh was composed of 16032 zones and 16531 grid points. For the numerical plate, there were 32 zones and 100 grid points. For the numerical sample, there were 16000 zones and 16441 grid points.

A strain softening model was used for the cylindrical sample. It was developed based on the MC model. Compared with the MC model, the strain softening model had additional input parameters: the cohesion table and the internal friction angle table. With those two parameters, the cohesion and internal friction angle of the materials can decrease with the increasing plastic shear strain. Therefore, this model can simulate the postpeak behaviour of materials.

The reason to use this strain softening model was that this model could simulate the postpeak behaviour of materials. Therefore, it is better in reflecting the mechanical behaviour of materials.

An elastic model was used for the square plates. The reason to use the elastic model to simulate the square plate was that in the experimental compressive test, the cementbased sample was compressed by the steel plate. Since the strength of the steel plate was much higher than the cementbased sample, failure only occurred in the cement-based sample. The steel plate consistently kept the elastic state. The input parameters for the cylindrical sample and the square plates are tabulated in Table 1.

The velocity of the plates was fixed. Moreover, the initial velocity of the top plate along the $z$-axis was set as $-1 \times 10^{-7}$ meters per step (minus represented that the velocity was along the negative direction of the $z$-axis). Since the velocity of the plate was fixed during the simulation process, the top plate would decline with a constant velocity. Additionally, no velocity was applied on the bottom plate. Consequently, the bottom plate would be stable in the whole simulation process. With this method, the sample in the middle would be compressed by the top plate to simulate the UCS process.

In the simulation process, the displacement along the $z$ axis of four grid points in the top plate was monitored, as shown in Figure 2.

Those four displacements were averaged as the uniaxial displacement of the sample, as shown in the following equation:

$$
s_{a}=\frac{s_{a 1}+s_{a 2}+s_{a 3}+s_{a 4}}{4},
$$

where $s_{a}$ is the axial displacement, $\mathrm{m}$, and $s_{a i}$ is the axial displacement of the grid point $i$ in the top plate, $m$.

In the UCS test, to calculate Poisson's ratio, the circumferential strain gauge was usually attached at the middle of the sample to record the circumferential displacement of the sample. Then, in this simulation, the circumferential displacement of four grid points at the middle of the outside surface of the sample was monitored. Those four displacements were also averaged as the circumferential displacement of the sample, as shown in the following equation:

$$
s_{c}=\frac{s_{c 1}+s_{c 2}+s_{c 3}+s_{c 4}}{4},
$$

where $s_{c}$ is the circumferential displacement of the sample, $\mathrm{m}$, and $s_{c i}$ is the circumferential displacement of the grid point $i$ at the middle of the outside surface of the sample, $\mathrm{m}$.

Since the bottom plate was stabilised in the whole simulation process, the reaction force along the $z$-axis of the grid points at the bottom surface of the bottom plate was summed. Then, this summed force was divided by the cross section area of the sample, and the result was regarded as the uniaxial compressive stress of the sample.

Then, the numerical UCS test was conducted. The stress to strain relationship of the sample is shown in Figure 3. In the numerical simulation, the UCS of the sample was $55.87 \mathrm{MPa}$.

In the experimental test, the UCS of the cement grout sample was $50.6 \mathrm{MPa}$, which was consistent with the numerical simulation results.

It also shows that in numerical simulation, after the stress of the sample reached the peak, the circumferential strain decreased. To check the reason, the circumferential displacement of a grid point was taken as an example and plotted. The grid point at the right middle of the sample (with an ID of 1430) was selected. The circumferential displacement of the grid point with the calculating time step is shown in Figure 4. The results show that before the calculating time step reached 6650, the circumferential displacement of the grid point increased. This indicated that the diameter of the sample at the middle increased because of the compression. However, after the calculating time step reached 6650, the circumferential displacement of the grid point started decreasing. This indicated that after the sample 


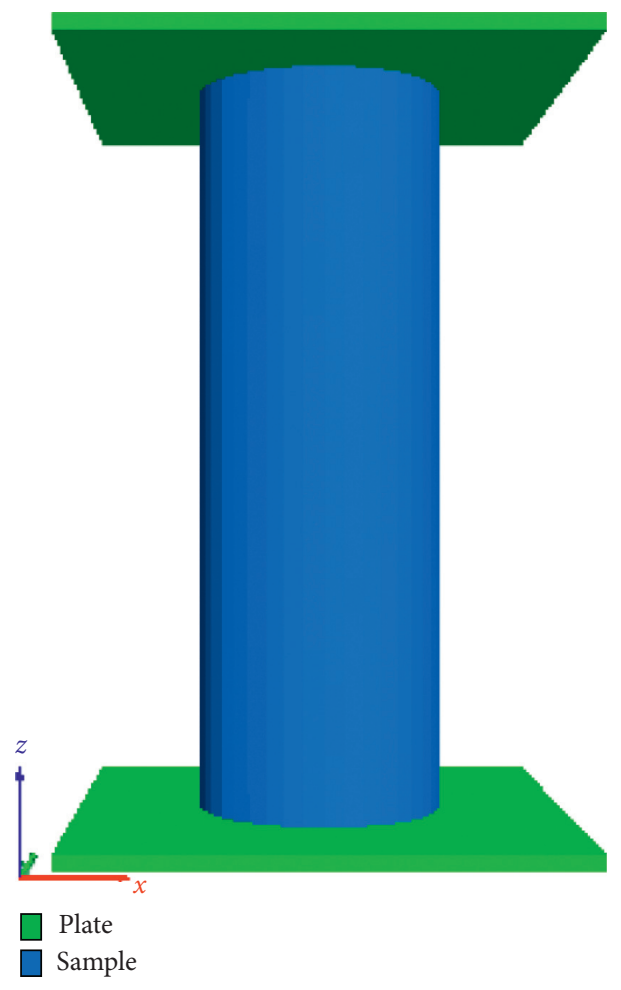

FIGURE 1: Geometry of the UCS test created in numerical simulation.

TABLE 1: Input parameters for the sample and the plate.

\begin{tabular}{lcc}
\hline Group & Input parameter & Value \\
\hline & Bulk modulus (GPa) & 8.44 \\
Sample & Shear modulus (GPa) & 5.06 \\
& Cohesion (MPa) & 19.3 \\
& Internal friction angle (degree) & 21 \\
Plate & Tension (MPa) & 2 \\
\hline
\end{tabular}

\begin{tabular}{|l|l} 
Slate \\
Sample \\
$X$-displ of gp 10002 \\
$X$-displ of gp 1430 \\
$Y$-displ of gp 3341 \\
$Y$-displ of gp 7581 \\
$Z$-displ of gp 12821 \\
$Z$ Z-displ of gp 16530 \\
$Z$-displ of gp 4576 \\
$Z$-displ of gp 8702
\end{tabular}

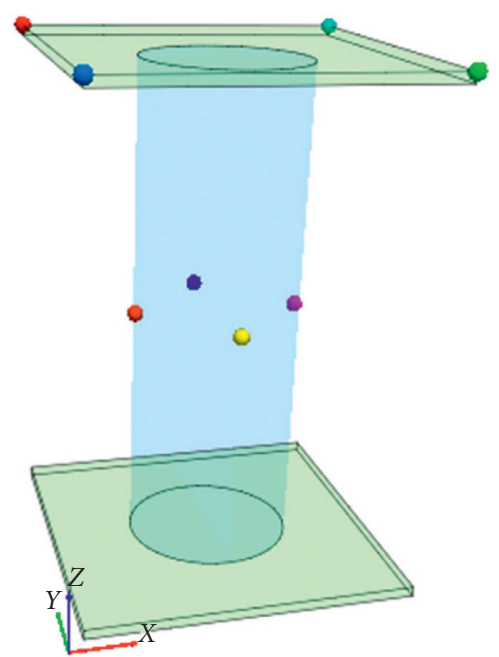

Figure 2: Grid points monitored in the simulation process. 


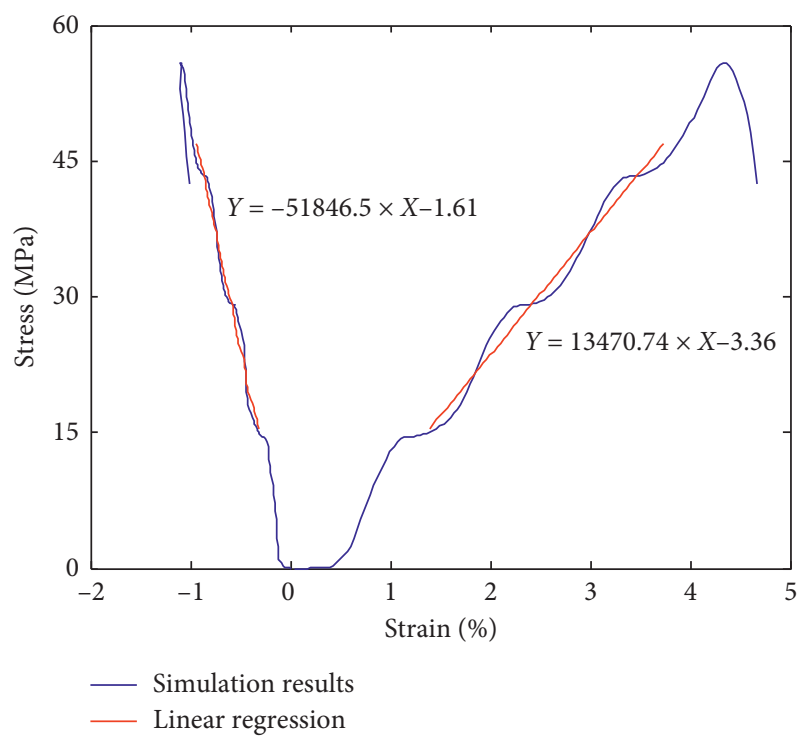

Figure 3: Stress to strain relationship of the cement grout sample.

reached the peak strength, the diameter of the sample in the middle also reached the peak. After the sample failed, the diameter of the sample in the middle started decreasing. This explained the phenomenon that after the sample reached the peak strength, the circumferential strain started decreasing.

Based on the numerical simulation, Young's modulus and Poisson's ratio can also be acquired. The results showed that Young's modulus in the numerical simulation was 13.47 GPa. Poisson's ratio can be calculated as follows [31]:

$$
\mu=-\frac{\varepsilon_{c}}{\varepsilon_{a}},
$$

where $\mu$ is Poisson's ratio; $\varepsilon_{c}$ is the circumferential strain of the sample; and $\varepsilon_{a}$ is the axial strain of the sample.

Then, Poisson's ratio can be calculated as 0.26 . Comparing Young's modulus and Poisson's ratio acquired from numerical simulation with those acquired from experimental tests, there was a close match between them, as shown in Table 2. This further confirmed that the input mechanical parameters were capable of simulating the cement grout.

3.1.2. Numerical Direct Shear Test and Validation. The input mechanical parameters used in the UCS simulation were then used in this section to simulate the direct shear process. Moosavi and Bawden [25] conducted experimental direct shear tests on cylindrical samples with a diameter of $100 \mathrm{~mm}$ and a length of $200 \mathrm{~mm}$. The test process was simulated in this section and the simulation result was then validated with experimental results.

In FLAC3D, a numerical cylindrical sample whose dimension was the same as the experimental sample was established. The sample was composed of two sections, namely, the top section and the bottom section. In the whole numerical model, there were 18000 zones and 19232 grid points. It should be mentioned that in the direct shear test, a shear failure plane is a predefined plane. Consequently, in numerical simulation, an interface was created at the middle of the sample, namely between the top section and the bottom section, to simulate the shear failure plane. The interface was composed of 49128 elements and 24725 nodes.

The constitutive law of the created interface was MC model and the input parameters of the interface are tabulated in Table 3.

The top section was fixed along the $x$-axis. For the bottom section, the external surface was fixed along the $x$ axis and $y$-axis. This was to simulate that, in the experimental test, the bottom sample was restricted by the shear box and no movement could occur. As for the bottom surface of the sample, it was fully fixed to simulate that, in the experiment, the whole sample was supported with a plate. A compressive normal stress of $2 \mathrm{MPa}$ was applied on the top surface of the sample. Then, this numerical model was calculated until the unbalanced force ratio decreased to $1 \times 10^{-5}$. With this method, the initial normal stress equilibrium condition was acquired. The normal stress distribution in the sample is shown in Figure 5. It is apparent to see that there was basically a uniform normal stress distribution in the sample. Under compression of the normal stress of $2 \mathrm{MPa}$, the normal stress in the sample was around $2 \mathrm{MPa}$.

Before the direct shear test was performed, the displacement along the shearing direction of four grid points at the top surface of the sample was monitored. In the simulation process, the displacements of those four grid points were averaged as the shear displacement of the sample.

It is more important to monitor the shear stress in the direct shear test process. To acquire this, in each step in the direct shear test process, each node on the interface was checked whether that node was still in contact. If it was, the shear force of that node was recorded and summed. The accumulated shear force was the whole shear force of the interface and was then divided by the area of the interface. The result was regarded as the shear stress of the interface.

Then, the direct shear test was performed. A shearing velocity of $1 \times 10^{-6}$ meters per step was applied on the top section of the sample. This velocity was kept constant in the whole simulation process to simulate the servo control. The direct shear test was conducted until the sample failed.

The comparison between the numerical simulation result and the experimental test result is shown in Figure 6. In the numerical simulation, when the shear displacement increased to $0.94 \mathrm{~mm}$, the shear stress of the interface increased to the peak of $6.48 \mathrm{MPa}$. After that, the shear stress decreased gradually. Also, there was a close match between numerical and experimental results. This confirmed that numerical simulation was capable of simulating the shear behaviour of the cement grout. It should be mentioned that this comparison was compared with the final shear displacement being less than $2 \mathrm{~mm}$.

In the shearing process, the averaged normal stress of the interface was also monitored. The variation of the normal stress on the interface is shown in Figure 7. Before the shear displacement increased to $0.94 \mathrm{~mm}$, the normal stress of the interface increased slightly to the peak of $2.15 \mathrm{MPa}$. After that, the normal stress of the interface decreased gradually. However, in the whole process, the minimum normal stress 


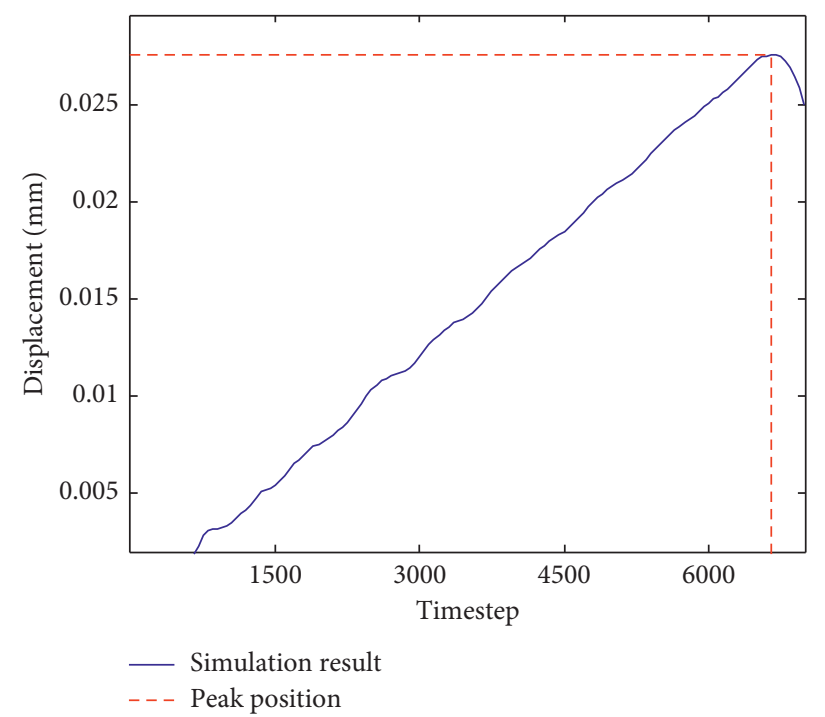

FIGURE 4: Circumferential displacement of the grid point at the right middle of the sample.

TABLE 2: Comparison between the mechanical properties of the cement grout acquired from laboratory tests conducted by Moosavi [23] and calculated from numerical simulation.

\begin{tabular}{lcc}
\hline Properties & Laboratory test & Numerical simulation \\
\hline UCS & 50.6 & 55.87 \\
Young's modulus $(\mathrm{GPa})$ & 12.66 & 13.47 \\
Poisson's ratio & 0.25 & 0.26 \\
\hline
\end{tabular}

TABLE 3: Input parameters for the interface.

\begin{tabular}{lcc}
\hline Group & Input parameter & Value \\
\hline & Normal stiffness $(\mathrm{GPa} / \mathrm{m})$ & 40 \\
Interface & Shear stiffness $(\mathrm{GPa} / \mathrm{m})$ & 8.28 \\
& Cohesion $(\mathrm{MPa})$ & 5.3 \\
& Friction angle (degree) & 30 \\
\hline
\end{tabular}

of the interface was $1.99 \mathrm{MPa}$, which was only a little bit smaller than the maximum normal stress of the interface. This indicated that in the direct shear process, the normal stress of the interface was not constant, although the applied normal stress was constant. This was probably due to the separation between the top sample and the bottom sample and the frictional failure of the interface.

After the direct shear test, a plot of the normal stress distribution on the interface is shown in Figure 8.

The results showed that the normal stress at the left side of the interface was zero. This was due to the separation of the top and bottom samples. Consequently, the interface was noncontact around the left side, as shown in Figure 9.

Since it is more important to study the state of the interface that was contacted, the stresses on the contacted interface were further studied. At the left side of the contacted interface, the normal stress was apparently much higher, with a maximum normal stress of $3.56 \mathrm{MPa}$. Moreover, the normal stress on the interface decreased towards the shearing direction. At the right side, the normal stress was much lower, with minimum normal stress around $0.75 \mathrm{MPa}$.
As for the shear stresses on the interface, their distribution is shown in Figure 10. Around the left side of the whole interface, the shear stress was also zero due to the noncontact of the interface.

As for the contacted interface, the shear stress distribution was apparently not uniform. At the left side of the contacted interface, the shear stress was much higher, with a maximum of $7.36 \mathrm{MPa}$. Then, the shear stress decreased towards the shearing direction. On the right side, the shear stress was relatively lower, with a minimum of around 6.0 MPa. This trend was basically consistent with the distribution of the normal stress on the interface.

However, attention should be paid that Figures 8 and 10 depicted the interface stress state after the test. In the middle shearing process, whether the distribution state was consistent with them was uncertain. And this will be studied in the following section.

After the direct shear test, the plastic state of the sample is shown in Figure 11. In this figure, "tension- $n$ " means that the zone was experiencing tensile failure now. "tension- $p$ " means that the zone previously experienced tensile failure. It is apparent to see that at the left side of the bottom sample, 


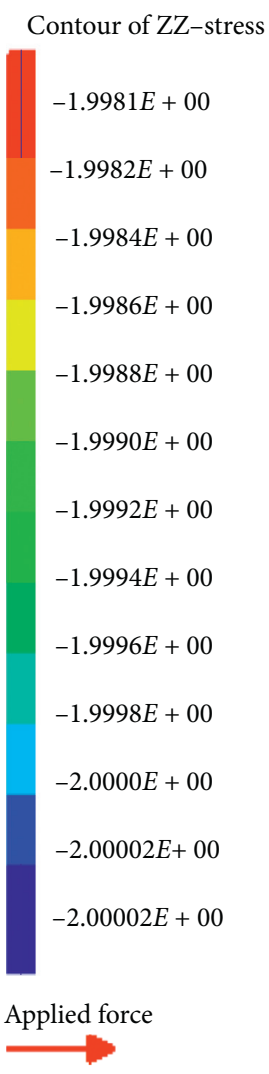

Unit: $\mathrm{MPa}$

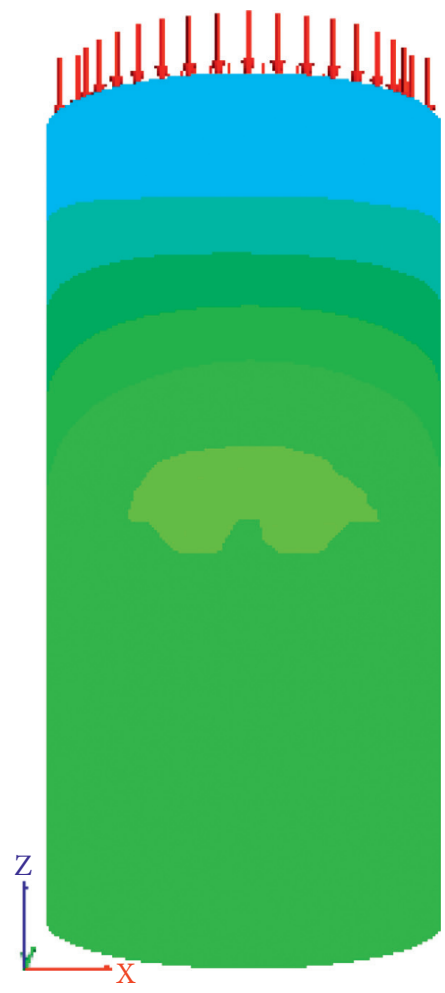

Figure 5: Normal stress distribution in the sample.

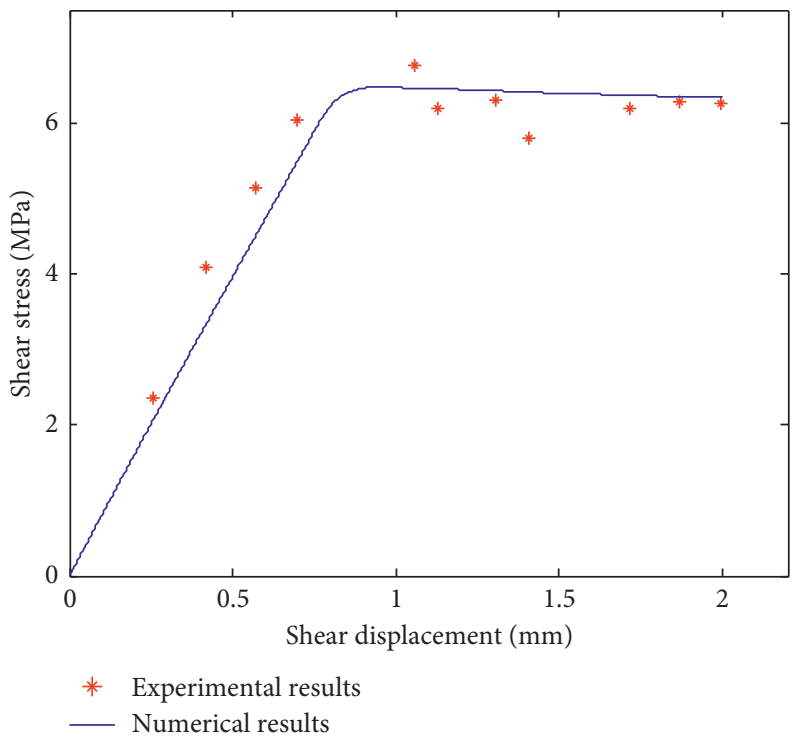

Figure 6: Comparison between numerical simulation result and the experimental test conducted by Moosavi and Bawden [25].

tensile failure occurred in the sample. Specifically, in the bottom sample, tensile failure occurred around the left side. In fact, this was consistent with the laboratory experimental test. Moosavi and Bawden [25] indicated that in the experimental test, tension crack occurred in the cement grout sample around the shear failure plane.
3.2. Simulation of the Cement Grout with a Lower Strength. Numerical simulation was also conducted on the same cement grout type while with relatively lower strength. First, the numerical UCS test was performed and compared with the experimental result to confirm the proper input parameters. 


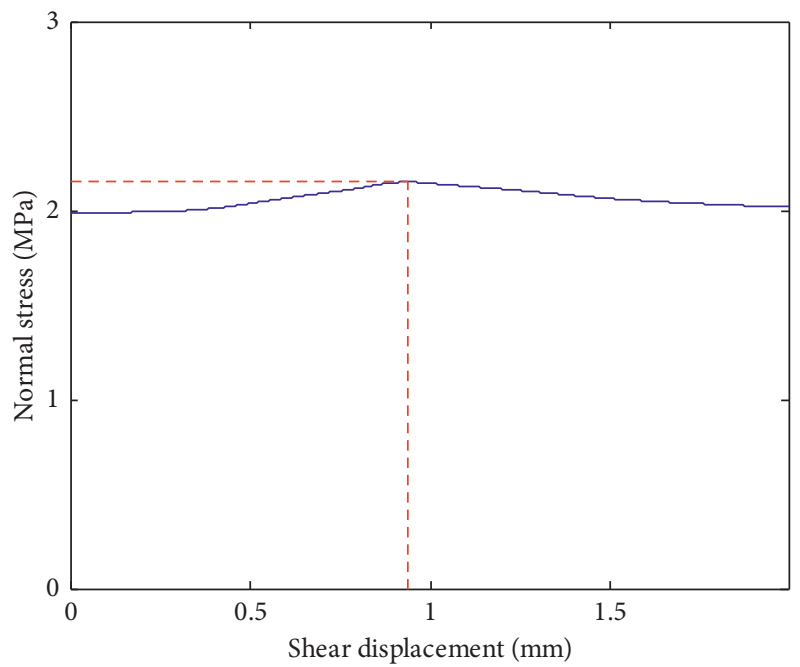

Figure 7: Variation of the normal stress of the shear failure plane.
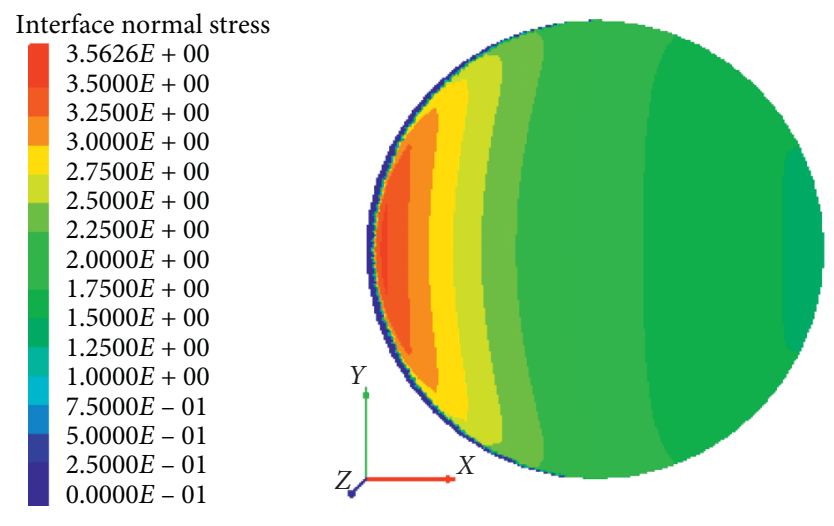

Unit: $\mathrm{MPa}$

FIGURE 8: Normal stress distribution on the shear failure plane.

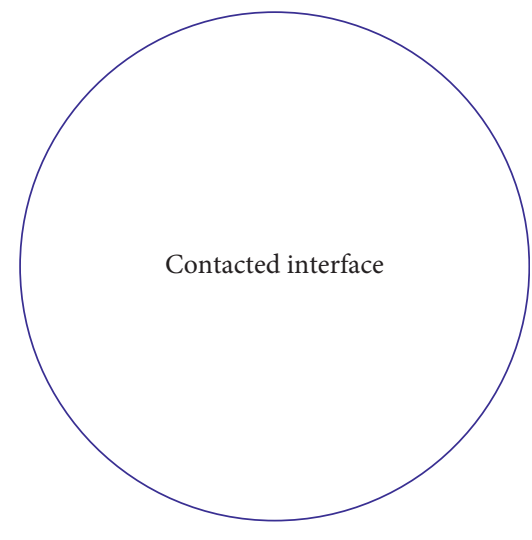

(a)

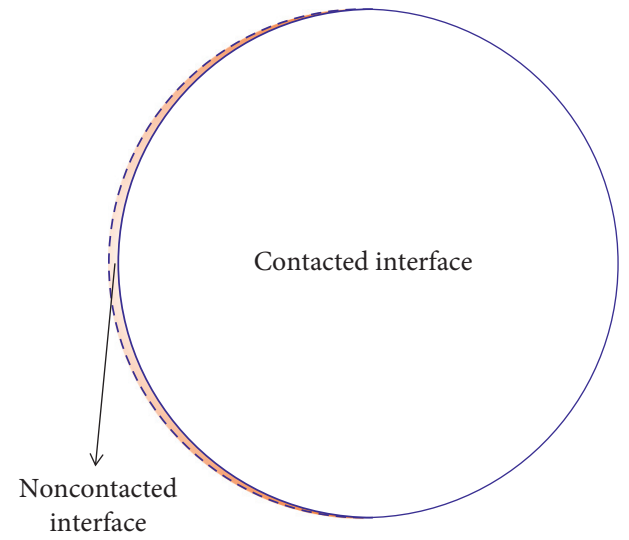

(b)

FIGURE 9: State of the interface in the direct shear test: (a) before the direct shear test; (b) after the direct shear test. 

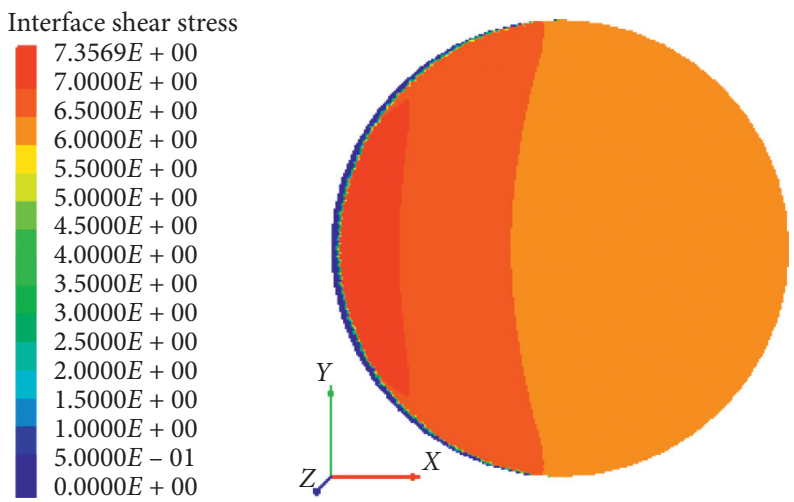

Figure 10: Shear stress distribution on the shear failure plane.

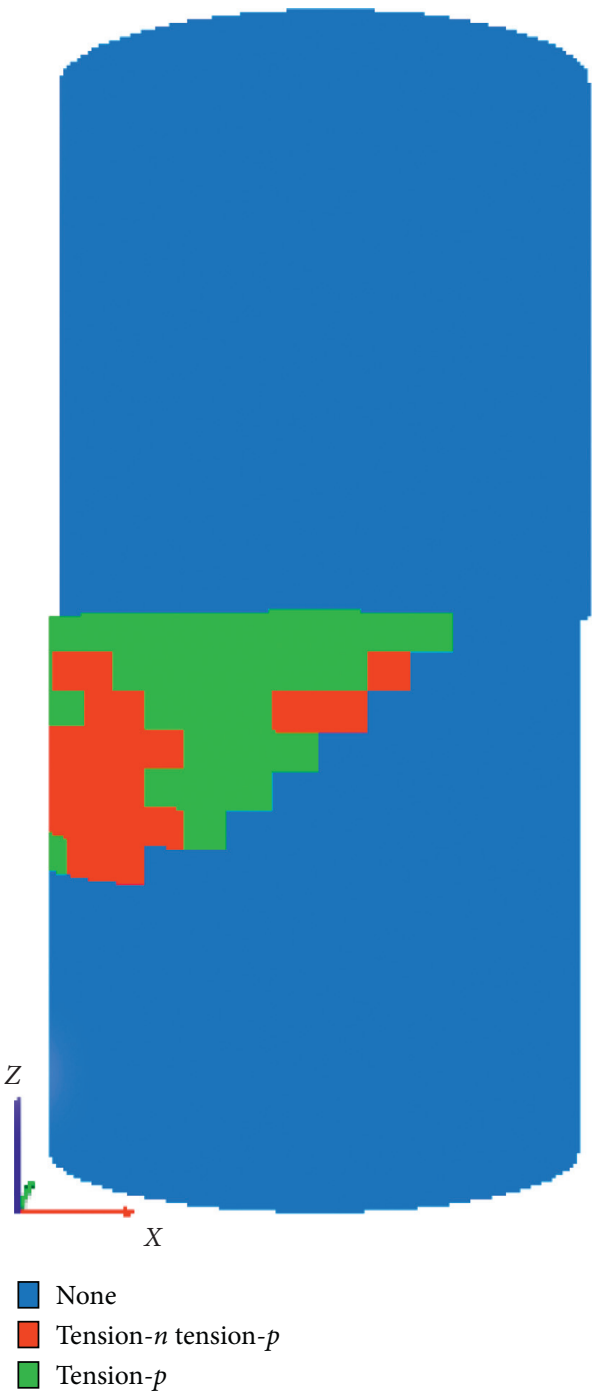

Figure 11: Plastic zone distribution in the sample.

3.2.1. Numerical UCS Test and Validation. The UCS test was simulated in FLAC3D. The simulation process was generally consistent with the procedures described in Section 3.1.1. Therefore, detailed simulation procedures were not described here. Only the simulation results were presented.
After the simulation, the stress to strain relationship of the sample was obtained. When the axial strain increased to $0.53 \%$, the axial stress of the sample reached a peak of 46.09 $\mathrm{MPa}$. In the experimental test, the measured UCS was 40.3 MPa. Therefore, there was a close match between them.

The Young's modulus and Poisson's ratio were also obtained. In the numerical simulation, Young's modulus and Poisson's ratio of the cement grout sample were 8.33 GPa and 0.26. A comparison between experimental and numerical results is shown in Table 4 . There was a good correlation between them. This further confirmed that the input parameters were robust for simulating the cement grout and can be used in the following direct shear test.

3.2.2. Numerical Direct Shear Test and Validation. Then, the numerical direct shear test was performed. And the input parameters of the sample were the same as those used in the UCS simulation. A comparison between the experimental and the numerical results is shown in Figure 12. In the numerical simulation, when the shear displacement increased to $1.41 \mathrm{~mm}$, the shear stress of the interface reached a peak, which was $6.02 \mathrm{MPa}$. Following this, the shear stress reduced gradually with the shear displacement. The results also showed that there was a good correlation between experimental and numerical results. This further confirmed the effectiveness of numerical simulation in evaluating the shear behaviour of the cement grout. Attention was paid that in this comparison, the maximum shear displacement was less than $1.8 \mathrm{~mm}$.

Also, the variation of the normal stress on the shear failure plane was checked. In the simulation process, the normal stress on the shear failure plane was not constant. It had a slightly increasing trend at the beginning and then decreased gradually.

\section{Analysis of the Shear Stress Distribution}

As mentioned in Section 3.1.2, Figures 8 and 10 showed that after the direct shear test, the normal stress and shear stress distribution on the shear failure plane were not uniform. However, in the middle process of the direct shear test, the normal stress and shear stress distribution state were uncertain. Therefore, in this section, the distribution of the 
TABle 4: Comparison between the experimental result reported by Moosavi [23] and calculated from numerical simulation.

\begin{tabular}{lcc}
\hline Properties & Laboratory test & Numerical simulation \\
\hline UCS & 40.3 & 46.09 \\
Young's modulus $(\mathrm{GPa})$ & 8.571 & 8.33 \\
Poisson's ratio & 0.25 & 0.26 \\
\hline
\end{tabular}

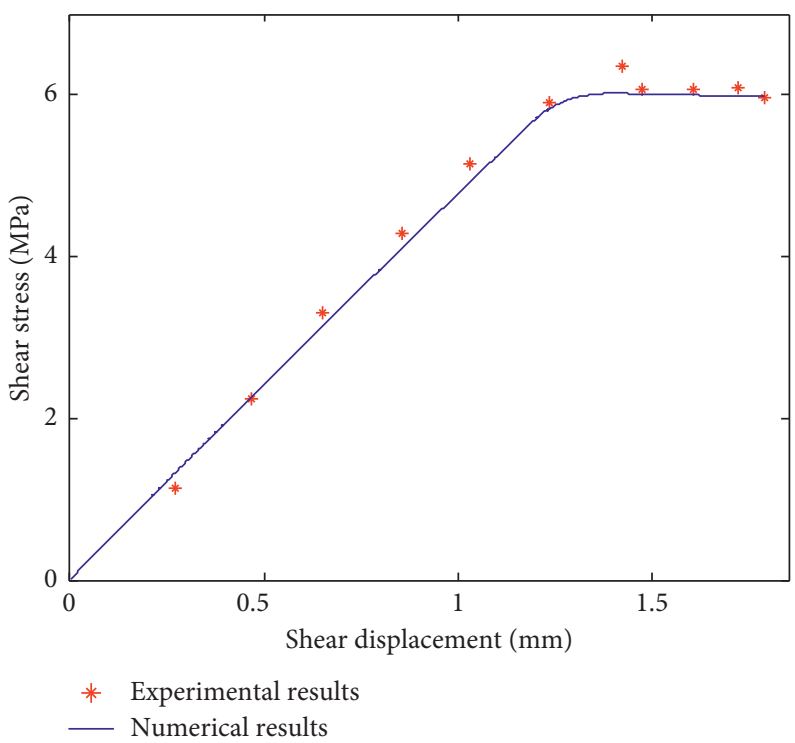

FIgURE 12: Comparison between the experimental result reported by Moosavi and Bawden [25] and the numerical simulation result.

shear stress and normal stress on the shear failure plane was further studied.

On the numerical shear stress versus shear displacement curve for the cement grout with a $w / c$ ratio of 0.4 , another three different points when the shear displacement increased to $0.6 \mathrm{~mm}, 0.94 \mathrm{~mm}$, and $1.2 \mathrm{~mm}$ were selected. At those points, the shear stress and normal stress distribution on the shear failure plane were plotted.

When the shear displacement was $0.6 \mathrm{~mm}$, the shear stress and normal stress distribution on the shear failure plane were shown in Figure 13. At this point, the shear stress distribution on the interface was generally uniform. On the contacted interface, the maximum shear stress was 4.97 $\mathrm{MPa}$, while the minimum shear stress was $4.63 \mathrm{MPa}$. The relative difference between the maximum and the minimum shear stresses was only $0.34 \mathrm{MPa}$ and the standard deviation was 0.09 . Since this relative difference was too small, it can be neglected.

As for the normal stress, on the contacted interface, there was a nonuniform distribution. Specifically, the maximum normal stress was around $2.96 \mathrm{MPa}$, while the minimum normal stress was around $1.69 \mathrm{MPa}$. The relative difference between the maximum and the minimum normal stresses was $1.27 \mathrm{MPa}$, and the standard deviation was 0.29 .

When the shear displacement increased to $0.94 \mathrm{~m}$, the distribution of the shear stress and normal stress is shown in Figure 14. Currently, there was an apparent nonuniform distribution of the shear stress on the contacted interface. On the left side, the shear stress was relatively higher, with a maximum of $7.33 \mathrm{MPa}$. As for the right side, the minimum was around $6.20 \mathrm{MPa}$. The relative difference between the maximum shear stress and minimum shear stresses was $1.13 \mathrm{MPa}$, and the standard deviation was 0.28 .

The results also revealed that the nonuniform distribution of the normal stress became more apparent. On the contacted interface, the maximum normal stress was 3.63 $\mathrm{MPa}$, occurring on the left side, while the minimum normal stress was $1.55 \mathrm{MPa}$, occurring on the right side. The relative difference between the maximum normal stress and minimum normal stress was $2.08 \mathrm{MPa}$, and the standard deviation was 0.5 .

When the shear displacement reached $1.2 \mathrm{~mm}$, the nonuniform shear stress distribution was still maintained, as shown in Figure 15. On the contacted interface, the maximum shear stress was $7.39 \mathrm{MPa}$, while the minimum shear stress was $6.18 \mathrm{MPa}$. The relative difference between the maximum shear stress and the minimum shear stress was 1.21 MPa, and the standard deviation was 0.29.

As for the normal stress distribution, it was still nonuniform. At the left side of the contacted interface, the normal stress was much higher, with a maximum of 3.61 $\mathrm{MPa}$. On the right side, the normal stress was smaller, with a minimum of $1.52 \mathrm{MPa}$. The relative difference between the maximum normal stress and minimum normal stress was $2.09 \mathrm{MPa}$, and the standard deviation was 0.5 .

The above three figures showed that at the beginning of the direct shear test, on the contacted area of the shear failure plane, the relative difference between the maximum shear 


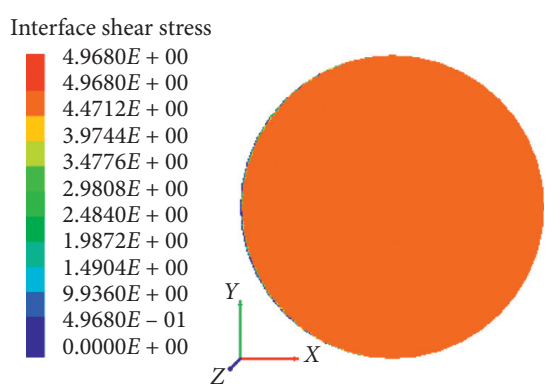

(a)

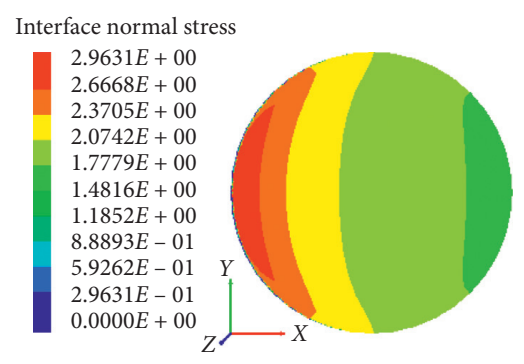

(b)

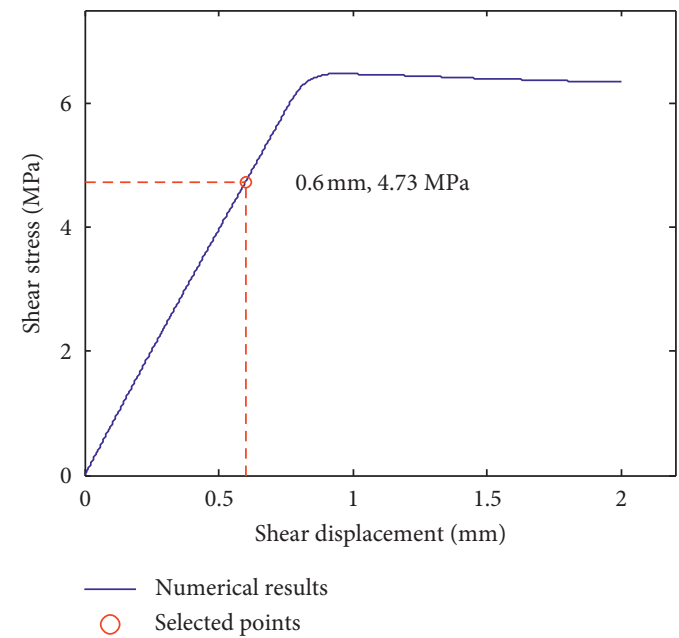

(c)

FiguRE 13: Distribution of the shear stress and normal stress on the shear failure plane when the shear displacement arrived at $0.6 \mathrm{~mm}$ : (a) shear stress distribution; (b) normal stress distribution; (c) point selected on shear stress-shear displacement curve.

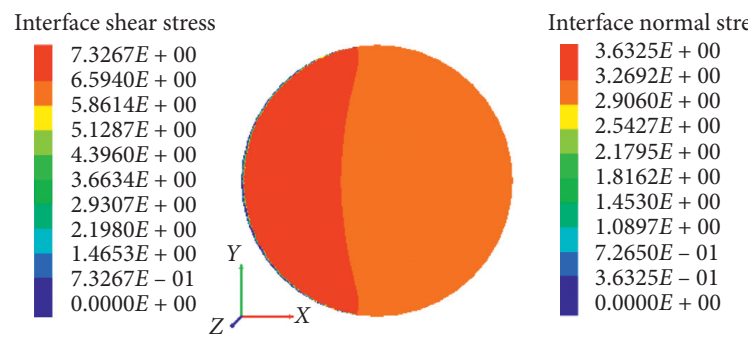

(a)

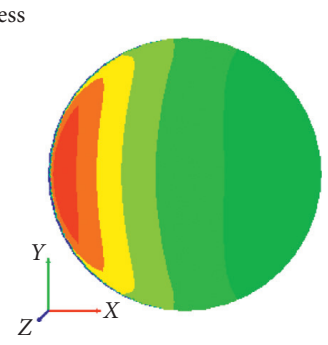

(b)

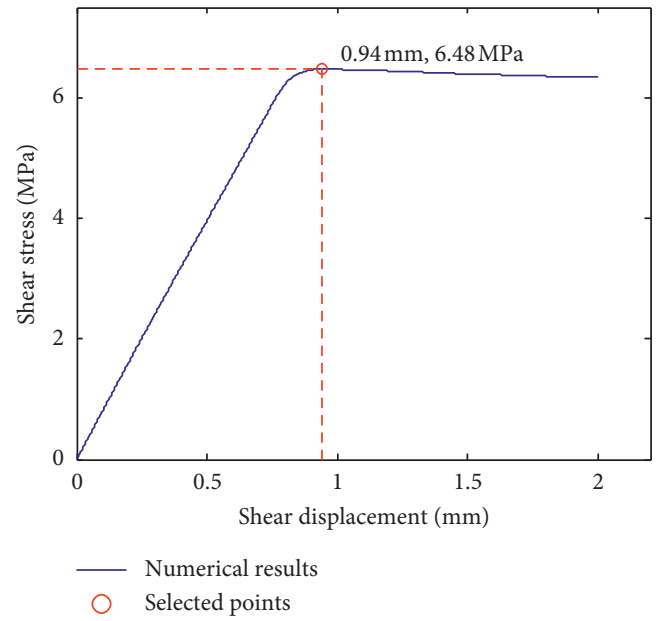

(c)

FIGURE 14: Distribution of the shear stress and normal stress on the shear failure plane when the shear displacement arrived at $0.94 \mathrm{~mm}$ : (a) shear stress distribution; (b) normal stress distribution; (c) point selected on shear stress-shear displacement curve.

stress and minimum shear stress was quite small. However, with the shear displacement increasing, the relative difference became larger.

To show the variation of the relative difference of the shear stresses, in the calculating process, the relative difference between the maximum shear stress and the minimum shear stress was monitored, as shown in Figure 16. When the shear displacement was smaller than $0.81 \mathrm{~mm}$, the relative difference of shear stresses was quite small. This indicated that in this stage, the shear stress could 


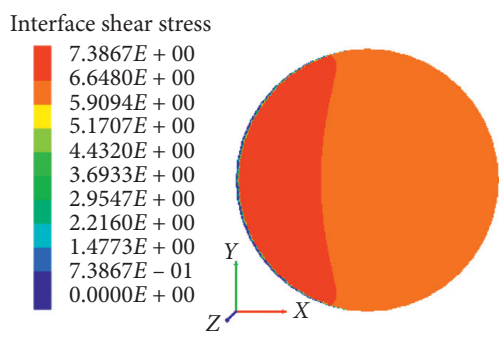

(a)
Interface normal stress

$3.6142 E+00$

$3.6142 E+00$

$3.2528 E+00$

$2.8914 E+00$

$2.5299 E+00$

$2.1685 E+00$

$1.8071 E+00$

$1.8071 E+00$

$1.4457 E+00$

$1.0843 E+00$

$7.2284 E+00$

$3.6142 E-01$

$0.0000 E+00$

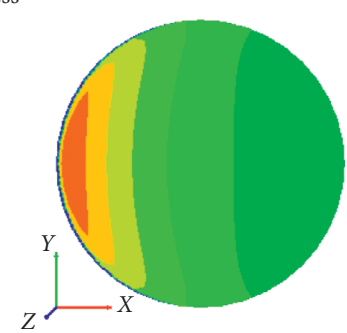

(b)

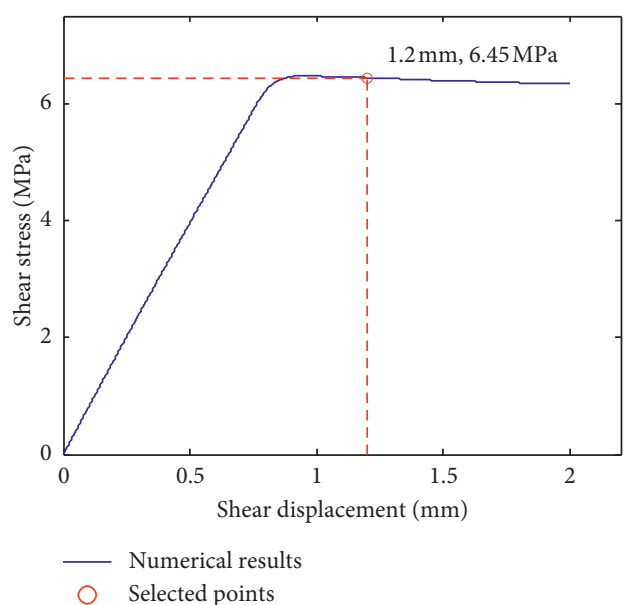

(c)

Figure 15: Distribution of the shear stress and normal stress on the shear failure plane when the shear displacement arrived at $1.2 \mathrm{~mm}$ : (a) shear stress distribution; (b) normal stress distribution; (c) point selected on shear stress-shear displacement curve.

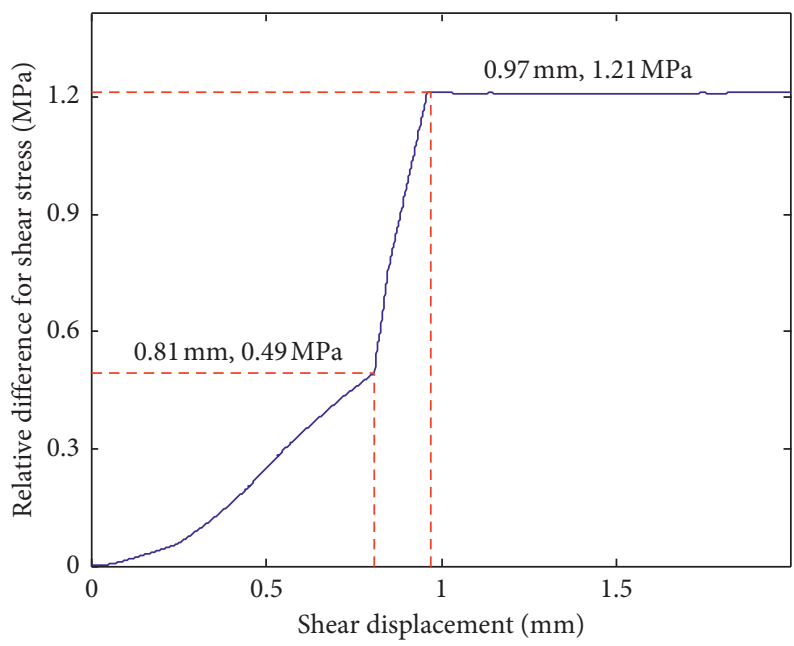

Figure 16: Variation of the relative difference of shear stresses in the numerical test.

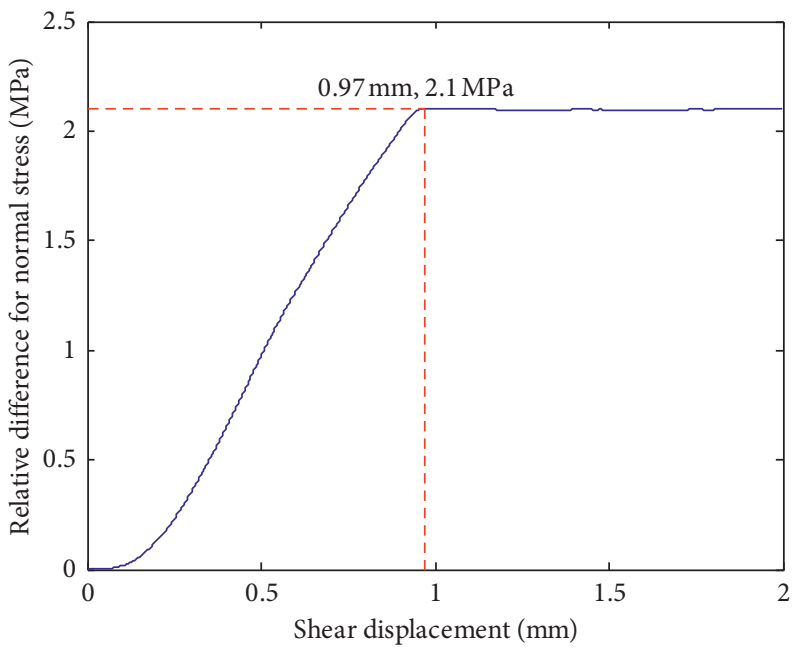

FIGURE 17: Variation of the relative difference of normal stresses in the numerical test. 
be regarded that it uniformly distributed on the shear failure plane. However, after that, the relative difference of the shear stresses increased dramatically. When the shear displacement increased to $0.97 \mathrm{~mm}$, which was around the shear strength point, the relative difference of the shear stresses was maximal. After that, the relative difference became almost constant.

Meanwhile, the relative difference between the maximum normal stress and minimum normal stress was monitored, as shown in Figure 17. It shows that before the shear displacement increased to $0.97 \mathrm{~mm}$, which was around the shear strength point, the relative difference increased monotonously. After that, the relative difference also became constant.

\section{Recommendation for Further Work}

Following the current study, the authors plan to continue the numerical study on the shear behaviour of cement grouts. Considering that the shear behaviour of cement grouts can also be studied with triaxial tests, the authors may use the numerical method to evaluate the mechanical response of cement grouts under the triaxial loading condition. Its purpose is to reveal the shear failure mechanism of cement grout during the triaxial loading process.

\section{Conclusions}

The shear behaviour of the cement grout plays a significant role in determining the stability of systems and structures in civil and mining engineering. To better understand the shear behaviour of the cement grout, numerical direct shear tests were performed with the FLAC3D software.

Cylindrical cement grout samples with two different strengths were established and numerically simulated. The numerical simulation results were compared with experimental results. There was a good correlation between them, confirming that numerical simulation can be used to evaluate the shear behaviour of the cement grout.

The numerical direct shear test results showed that in the shearing process, along the shear failure plane, the shear stress at each point was not identical. There was a shear stress distribution on the contacted shear failure plane. At the beginning of the direct shear test, the relative difference of the shear stresses was quite small. Then, in this stage, it can be assumed that there was a uniform shear stress distribution on the contacted shear failure plane. However, once the shear displacement increased to around the shear strength point, the relative difference of the shear stresses became much larger. In this stage, the shear stress was nonuniformly distributed on the contacted shear failure plane. After that, the relative difference of the shear stress became stable.

Additionally, although the applied normal stress on the sample was constant, the normal stress on the contacted shear failure plane was variable. Before the shear strength point, the normal stress increased slightly. After that, the normal stress gradually decreased. There was also a distribution of the normal stress on the contacted shear failure plane. This normal stress distribution was not apparent at the beginning of the test. However, when the shear displacement increased to around the shear strength point, it became much obvious. Moreover, after that, this nonuniform normal stress distribution became stable.

\section{Data Availability}

The data used to support the findings of this study were included in the article.

\section{Conflicts of Interest}

The authors declare that they have no conflicts of interest.

\section{Acknowledgments}

This study was supported by the National Natural Science Foundation of China (51904302 and 52034009), the Yue Qi Distinguished Scholar Project (800015Z1179), and the Fundamental Research Funds for the Central Universities (2021YQNY05).

\section{References}

[1] Z. Wang and Y. Song, "Adsorption properties of CFBC ashcement pastes as compared with PCC fly ash-cement pastes," International Journal of Coal Science \& Technology, vol. 3, no. 1, pp. 62-67, 2016.

[2] S. Tang, Y. Wang, Z. Geng et al., "Structure, fractality, mechanics and durability of calcium silicate hydrates," Fractal and Fractional, vol. 5, no. 2, Article ID 5020047, 2021.

[3] L. Wang, T. He, Y. Zhou et al., "The influence of fiber type and length on the cracking resistance, durability and pore structure of face slab concrete," Construction and Building Materials, vol. 282, Article ID 122706, 2021.

[4] S. Wang, D. Li, C. Li, C. Zhang, and Y. Zhang, "Thermal radiation characteristics of stress evolution of a circular tunnel excavation under different confining pressures," Tunnelling and Underground Space Technology, vol. 78, pp. 76-83, 2018.

[5] M. Ghadimi, K. Shahriar, and H. Jalalifar, "Study of fully grouted rock bolt in tabas coal mine using numerical and instrumentation methods," Arabian Journal for Science and Engineering, vol. 41, no. 6, pp. 2305-2313, 2016.

[6] M. Wang, J. Bai, W. Li, X. Wang, and S. Cao, "Failure mechanism and control of deep gob-side entry," Arabian Journal of Geosciences, vol. 8, no. 11, pp. 9117-9131, 2015.

[7] L. Wang, F. Guo, Y. Lin, H. Yang, and S. Tang, "Comparison between the effects of phosphorous slag and fly ash on the $\mathrm{C}-\mathrm{S}-\mathrm{H}$ structure, long-term hydration heat and volume deformation of cement-based materials," Construction and Building Materials, vol. 250, Article ID 118807, 2020.

[8] R. F. Feldman and J. J. Beaudoin, "Microstructure and strength of hydrated cement," Cement and Concrete Research, vol. 6, no. 3, pp. 389-400, 1976.

[9] P. L. Domone and H. Thurairatnam, "Development of mechanical properties of ordinary Portland and Oilwell B cement grouts," Magazine of Concrete Research, vol. 38, no. 136, pp. $129-138,1986$.

[10] A. J. Hyett, W. F. Bawden, and A. L. Coulson, "Physical and mechanical properties of normal Portland cement pertaining to fully grouted cable bolts," in Proceedings of the International Symposium on Rock Support, Rock Support in Mining 
and Underground Construction, pp. 341-348, Sudbury, Ontario, Canada, June 1992.

[11] A. Boumiz, C. Vernet, and F. C. Tenoudji, "Mechancial properties of cement pastes and mortars at early ages," Advanced Cement Based Materials, vol. 3, no. 1996, pp. 94-106, 1996.

[12] H. Li, H. Xiao, and J. Ou, "A study on mechanical and pressure-sensitive properties of cement mortar with nanophase materials," Cement and Concrete Research, vol. 34, no. 3, pp. 435-438, 2004.

[13] A. Mirza, N. Aziz, W. Ye, and J. Nemcik, Mechanical Properties of Grouts at Various Curing Times, Coal Operators' Conference, University of Wollongong, Wollongong, Australia, 2016.

[14] S. Ma, X. Zhu, W. Qin, and S. Hu, "Determination of the bond-slip relationship of fully grouted rockbolts," Environmental Earth Sciences, vol. 77, no. 9, pp. 325-326, 2018.

[15] J. Chen, H. Zhao, F. He, J. Zhang, and K. Tao, "Studying the performance of fully encapsulated rock bolts with modified structural elements," International Journal of Coal Science and Technology, vol. 8, no. 1, pp. 1-13, 2021.

[16] J. Chen, D. Xin, and J. Zhang, "Analytical studying of the confining medium diameter impact on bearing capacity of rock bolts," Mathematical Problems in Engineering, vol. 20218 pages, Article ID 6680886, 2021.

[17] A. J. Hyett, W. F. Bawden, and R. D. Reichert, "The effect of rock mass confinement on the bond strength of fully grouted cable bolts," International Journal of Rock Mechanics and Mining Science \& Geomechanics Abstracts, vol. 29, no. 5, pp. 503-524, 1992.

[18] P. Simms and M. Grabinsky, "Direct measurement of matric suction in triaxial tests on early-age cemented paste backfill," Canadian Geotechnical Journal, vol. 46, no. 1, pp. 93-101, 2009.

[19] Y. Sakai, M. Nakatani, A. Takeuchi, Y. Omorai, and T. Kishii, "Mechanical behavior of cement paste and alterations of hydrates under high-pressure triaxial testing," Journal of Advanced Concrete Technology, vol. 14, no. 1, pp. 1-12, 2016.

[20] N. Aziz, D. Majoor, and A. Mirzaghorbanali, "Strength properties of grout for strata reinforcement," Procedia Engineering, vol. 191, pp. 1178-1184, 2017.

[21] J. Chen and $\mathrm{C}$. $\mathrm{Xu}$, "A study of the shear behavior of a Portland cement grout with the triaxial test," Construction and Building Materials, vol. 176, pp. 81-88, 2018.

[22] Z. Zhang, M. Deng, J. Bai, X. Yu, Q. Wu, and L. Jiang, "Strain energy evolution and conversion under triaxial unloading confining pressure tests due to gob-side entry retained," International Journal of Rock Mechanics and Mining Sciences, vol. 126, pp. 1-10, 2020.

[23] M. Moosavi, Load Distribution along Fully Grouted cable Bolts Based on Constitutive Models Obtained from Modified Hoek Cells, Queen's University, Kingston, Canada, 1997.

[24] S. Wang, H. G. Xiao, Z. S. Zou, C. Cao, Y. H. Wang, and Z. L. Wang, "Mechanical performances of transverse rib bar during pull-out test," International Journal of Applied Mechanics, vol. 11, no. 5, pp. 1-15, 2019.

[25] M. Moosavi and W. F. Bawden, "Shear strength of Portland cement grout," Cement and Concrete Composites, vol. 25, no. 7, pp. 729-735, 2003.

[26] G. Lu and K. Wang, "Investigation into yield behavior of fresh cement paste: model and experiment," ACI Materials Journal, vol. 107, no. 1, pp. 12-19, 2010.
[27] J. J. Assaad, J. Harb, and Y. Maalouf, "Measurement of yield stress of cement pastes using the direct shear test," Journal of Non-Newtonian Fluid Mechanics, vol. 214, pp. 18-27, 2014.

[28] J. Chen, P. C. Hagan, and S. Saydam, "Shear behaviour of a cement grout tested in the direct shear test," Construction and Building Materials, vol. 166, pp. 271-279, 2018.

[29] W. Li, F. U. A. Shaikh, L. Wang et al., "Experimental study on shear property and rheological characteristic of superfine cement grouts with nano- $\mathrm{SiO}_{2}$ addition," Construction and Building Materials, vol. 228, pp. 1-11, 2019.

[30] J. Chen, S. Saydam, and P. C. Hagan, "Numerical simulation of the pull-out behaviour of fully grouted cable bolts," Construction and Building Materials, vol. 191, pp. 1148-1158, 2018.

[31] X. Li, Z. C. Grasley, J. W. Bullard, and E. J. Garboczi, "Computing the time evolution of the apparent viscoelastic/ viscoplastic Poisson's ratio of hydrating cement paste," Cement and Concrete Composites, vol. 56, pp. 121-133, 2015. 